\title{
The mediating role of planned behaviour on deterrence initiatives aimed at managing local government workplace compliance
}

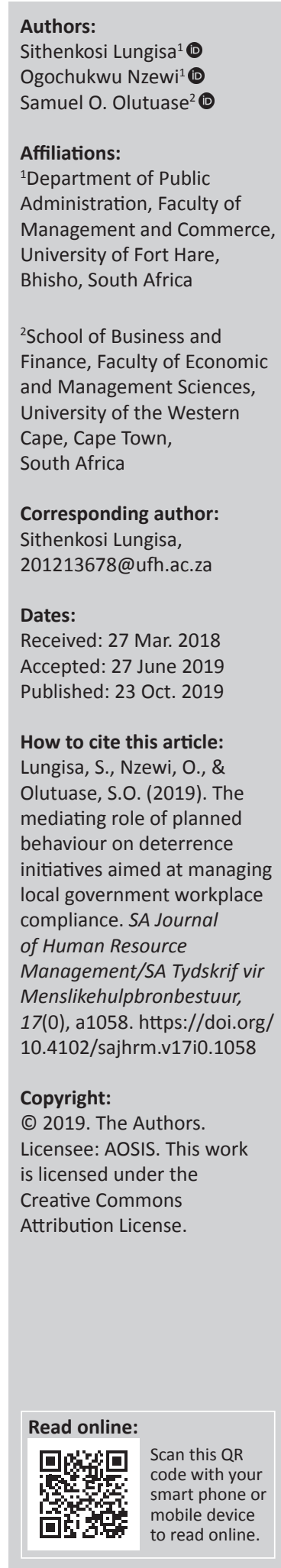

Orientation: Compliance culture within the South African local government context is perceived to be critical to sustainable municipality service delivery. Improving compliance culture is therefore important.

Research purpose: This article therefore developed a compliance framework based on deterrence theory (DT) and the theory of planned behaviour (TPB) to identify human behavioural factors to be considered in the development and use of work procedures as a way to improve workers' compliance with work procedures.

Motivation for the study: Reports (e.g. Auditor General reports) on municipality service delivery fall short of providing a clear assessment and study of work and human behavioural dynamics in relation to compliance with work procedures.

Research approach/design and method: This article tested a conceptual model focused on the effect of deterrence initiatives on workplace compliance as mediated by the theory-planned behaviour. Data were collected from 119 workers in two municipalities of the Eastern Cape Province in South Africa through a structured questionnaire and analysed using structural equation model.

Main findings: Findings show that a positive attitude towards compliance to work procedures cannot be achieved through intimidation; reinforcement has a positive effect on attitude, subjective norms and perceived behavioural control (PBC). However, only the PBC aspect of the TPB explains significant mediation between deterrence and compliance.

Practical/managerial implications: The study demonstrates how compliance culture can be engendered by non-intimidating deterrent measures and PBC.

Contributions/value-add: The negative effect of intimidation on compliance culture and the positive effect of $\mathrm{PBC}$ on compliance attitude of workers are critical contributions.

Keywords: compliance; theory of planned behaviour; deterrence theory; work procedures; local government.

\section{Introduction}

Understanding organisational behaviour is critical for the effective management of human resources. There is consensus among scholars that the concept is essential in cultivating a culture of compliance towards work procedures. The insinuation here is that employee behavioural management is cardinal in driving the institutions and organisation forward. In recent years, however, human resources management (HRM) has come under major scrutiny, especially in the South African local government context where sustainable service delivery still remains a challenge. This is partly attributable to the lack of a compliance culture in relation to following work procedures on the part of both the managers and the employees (AGSA, 2016). Nzewi (2017) argues that informal application of work procedures seems to be widely evident in the local government context because of a plethora of administrative factors such as limited communication and lack of documentation among others. Despite this state of affairs, most government reports such as the Auditor General (2016), the local government turnaround strategy (2009) and the back to basics policy (2014) are mute on providing in-depth analyses on, as well as solutions to, the internal challenges of compliance faced by municipalities. In particular, these reports fall short of providing a clear assessment and study of work and human dynamics in relation to compliance with work procedures and legislative provisions that govern them. 
In a bid to cover this void in the literature and weaknesses in the practice of compliance to work procedures in the local government context, this study used the deterrence theory (DT) and the theory of planned behaviour (TPB) to identify behavioural factors to be considered important in the development and use of work procedures. Work procedures in this sense are viewed as organisational design statements or rules that can be strategically employed to improve compliance with legislation and regulations applying to local government. In this regard, the study sought to determine the mediating role of planned behaviour on deterrence initiatives aimed at managing local government workplace compliance. As a result, a conceptual model testing the mediating role of planned behaviour on deterrence initiatives at managing workplace compliance was developed and tested in two selected municipalities in the Eastern Cape Province, the Oliver Tambo District Municipality and Buffalo City Metropolitan Municipality. To this end, the article sought to answer two questions:

1. What is the mediating role of planned behaviour on deterrence initiatives aimed at managing local government workplace compliance?

2. How valid are the TPB and DT hypothetical models for managing workplace compliance to work procedures?

\section{Theoretical framing}

A review of the relevant theories guiding this study is prudent in exploring and articulating the nexus between theories and employee compliance to work procedures. Based on the South African local government's experiences on the adoption and practice of work procedures, the study hinged on DT and the TPB in informing the development of the proposed model.

\section{Theory of planned behaviour}

The TPB, whose main architects are Ajzen and Fishbein (1973):

[I]s a social-psychological theory that explains behavioural decision-making processes of human beings with aiming at understanding and predicting the behaviour of individuals, advocating that the successful completion of human behaviours are mainly controlled by individual will. (Zhang, 2018, p. 76)

The main tenets in relation to this include three primary assumptions, which are (1) attitude, (2) subjective norm (SN) and (3) perceived behavioural control (PBC). Ajzen (2006, p. 35) defines attitude as 'a learned predisposition to respond to an object or class of objects in a consistently favourable and unfavourable way'. Attitude towards the act (AAct), however, is defined as the degree to which performance of the behaviour is positively or negatively valued by an individual (Ajzen, 2006). In the light of the definitions, this study adopts Ajzen's (2005, p. 30) definition of attitude as a disposition to respond favourably or unfavourably to an object, person or institution.

More so, SN is defined by Conner, Norman and Bell (2002, p. 197) 'as a function of normative beliefs, which represent perceptions of specific significant others' preferences about whether one should or should not engage in a behaviour'. According to Ajzen (1991, p. 195), 'normative beliefs are concerned with the likelihood that important referent individuals or groups approve or disapprove of performing a given behaviour'. In other words, SNs deal with people with the ability to influence others (Fishbein \& Ajzen, 2010).

Perceived behavioural control refers mainly to people's perceptions of their ability to perform a given behaviour (Ajzen, 2006). In the TPB, PBC is determined by the total set of accessible control of factors that may facilitate or impede the performance of the behaviour. To be specific, the strength of each control belief (c) is weighted by the perceived power $(\mathrm{P})$ of the control factor, and the products are aggregated (Ajzen, 2006). Perceived behavioural control can also predict behaviour directly to the extent that the measure matches actual control.

In this research study, the assumptions and antecedents of TPB are used to measure the relevance and importance of managing workplace compliance to accelerate organisational performance and simultaneously to enforce the culture of compliance to work procedures among the employees. This is largely based on the notion that the local government (sphere) is underpinned by non-compliance with legislative and regulatory frameworks, which hinders effective municipal performance and service delivery (Ijeoma \& Nzewi, 2016). The intent of this study was to determine the mediating role of planned behaviour on deterrence initiative aimed at managing local government workplace compliance.

\section{Deterrence theory}

The roots of the modern-day DT date back to the era when the United States was coming into existence (Johnson, 2019). The main proponents of the theory are Ceasare Beccaria who wrote essay on Crimes and Punishments in 1764 and Jeremy Bentham who wrote An Introduction to the Principles of Morals and Legislation (Introduction to the Principles) in 1781. These philosophers emphasised the notion that 'punishment must be proportionate to the crime committed and that punishment should occur as immediately after the commission of a crime' (Johnson, 2019, p. 3). Therefore, under DT, an individual is punished for breach of a rule or law, and this serves as a lesson for the rest of the society. Through this, a clear message is conveyed, which outlines what is right or wrong and consequences for such actions are indicated. In deterrence, punishment is viewed as a medium or tool for communicating a message, with the intention of stimulating individuals' conscious and unconscious thoughts against committing an offence (Bates, Darvell, \& Watson, 2017, p. 27). This will result in the development of a habitual culture of compliance with procedures and law within a society (Hawkin, 1969).

According to Schneider (2019, p. 1), the concept of deterrence 'focuses on the use or the threat of punishment, with the intention to avoid people breaking the law that governs the coexistence of a society'. This is relevant in the study of 
municipal employee behaviour because most deviants are often public office holders who occupy the top rungs of the administrative machinery and their subordinates. Noteworthy, non-compliance to work procedures directly or indirectly reduces an organisation's competitive advantage. In this regard, the DT emphasises the need to abide by the law, and failure to that, organisational employees have to face punishment.

Beyleveld (1979, p. 207), in his contribution to DT, argues that at the centre of the effectiveness of deterrence is the consistent application of sanctions. He eludes that through sanctions, an individual is deterred from committing an offence because he fears the application of the sanction. In essence, sanctions act as the primary stimulator of the fear of intimidation found in the deterrent effect (Beyleveld [1979] cited in Bates et al., 2015, p. 24). Elliott (2003), in the light of Beyleveld's (1979) definition, alludes that deterrence is therefore pivotal in ensuring compliance with rules and laws. Elliot (2003) further outlines how deterrence operates, explaining that the introduction of sanctions deters and prevents an offence in the following ways:

- A clear knowledge of consequences associated with the breach of legislation and regulation invokes individual perception on costs of offending that results in compliance being seen to be more attractive than offending.

- At the centre of sanctions is moral education, which stimulates a culture of habit to comply with legislation and regulation.

- Implementation of sanctions on breach of law is pivotal than merely providing threats.

- Through punishment of an individual on breach of law, offences can be reduced by capacitating potential offenders and reforming offenders, which results in informal pressure to comply.

Therefore, this study uses DT to develop and present a work and human dynamic compliance-based model through which municipalities can improve legislative and regulatory framework compliance, which has been a recurring challenge for municipal performance. In the next section, the article presents how these theories are applicable in terms of the proposed context of local government performance.

\section{Application of theory of planned behaviour and deterrence theory in local government}

Among the many challenges of local government, noncompliance with legislation and regulatory frameworks is weightier than others (Nzewi, 2017). Therefore, it is important to understand the challenges of the South African local governance (Ijeoma \& Nzewi, 2016). Thus, this study identified the TPB and the DT as possible foundations for the design of work procedures for organisational compliance towards improved performance and service delivery in local government. To our knowledge, very few studies have focused on organisational compliance using TPB. Nzewi (2017) developed a TPB-based conceptual framework to manage municipal audit compliance through work procedures. However, Nzewi's (2017) conceptual framework fell short of providing strategies on how the antecedents of the TPB will be strengthened to ensure a culture of audit compliance through work procedures.

Herath and Rao (2009) used both the TPB and DT to examine employee security compliance intentions. Their study identified that the antecedents of the TPB need to be supplemented by a theory that ensures conduct with law; hence, their study emphasised the adoption of the DT. Deterrence theory focuses on the notion that punishment must be used on employees who fail to abide by the set rules and regulations. At the heart of this study is the exploration of the interplay between the DT and the TPB to ensure that compliance with work procedures is achieved at local government domain.

The main objective of this research study was to find out the mediating role of planned behaviour on deterrence initiatives aimed at managing local government workplace compliance. However, in the review of the two theories, shortcomings were identified with the TPB, answering only the objective of how these human behavioural factors can be identified and falling short on how compliance will be instilled in the culture of the organisation, and hence the introduction of the DT, which focuses fundamentally on the consequences of non-compliance with work procedures. Therefore, in essence, these two theories supplement each other in the sense that TPB focuses on studying and influencing human behaviour and DT provides strengthening mechanisms that influence the already studied human behaviour by TPB. Thus, this study employed a mixed model of the DT and the TPB as a way to ensure that designed work procedures are cognisant of the social and behavioural factors of municipal officials.

This study focused on three variables: DT, TPB and intention to comply (ITC). The study examined the influence of deterrence on ITC, and the TPB was used as an intervening variable that intended to test if the influence of deterrence on ITC was persistent with the inclusion of TPB. Each of the two theories was composed of three antecedents: DT (intimidation, education and reinforcement) and TPB (attitude, SNs and PBC). In this regard, a hypothetical model was developed to test the relationship between deterrence and ITC and the effect of planned behaviour on that relationship.

In this case, the ITC with legislative and regulatory frameworks will be influenced by attitude, SNs and PBC. However, the study strongly argues that the TPB lacks in terms of what may prevent or deter a negative behaviour once the antecedents of the theory have been stimulated or enhanced. Therefore, the DT proposes that unwanted behaviour can be prevented through deterrent effect (intimidation), strengthening of moral inhibitions (education) and stimulation of habitual law-abiding conduct (reinforcement) (Williams \& Hawkins, 1986). The following hypotheses were made in the context of work procedure compliance: 
H1a: Attitude towards compliance with work procedures influences the intention to comply with legislation and regulation.

H1b: Subjective norms with work procedures influence the ITC with legislation and regulation.

H1c: Perceived behavioural control with work procedures influences the intention to comply with legislation and regulation.

Deterrence theory is mostly used in the discipline of criminology. Peace, Galletta and Thong (2003), in their examination of organisational software piracy, found that the severity of punishment influences piracy attitudes in organisational software. The study also found that imposing penalties on organisational software piracy can lead to prevention of certain behaviour. Thus, Herath and Rao (2009) suggest that if actions of an employee result in the breach of work procedures, the organisation must investigate the offence and the employee should be punished through imposing a penalty. Thus, the employee will perceive the severity of punishment for non-compliance to be high, and their intention to commit undesired behaviours is likely to decline as a result. Therefore, the study hypothesised that:

H2a: The deterrent effect (intimidation) influences attitude towards compliance with work procedures.

H2b: The deterrent (intimidation) influences SNs towards compliance with work procedures.

H2c: The deterrent effect (intimidation) influences PBC to comply with work procedures.

Wikström (2010) argues that, without fear of punishment and moral constraints, individuals are most likely to display a higher prospect of offending in any given scenario. Therefore, his study intended to answer the following questions: what influences people to break moral rules? Do these individuals view the behaviour as a viable alternative? (Wikström, 2010). In this regard, if the individual perceives monitoring to be effective and sanction thereof to be severe, this may create deterrence. Thus, out of fear of consequence, which acts as a factor in any thought over whether or not to perform a motivation and break a moral rule or law, deterrence is created (Wikström \& Treiber, 2007, p. 245). This study therefore hypothesised that:

H3a: Strengthening moral inhibition (education) influences attitude towards compliance with work procedures.

H3b: Strengthening moral inhibition (education) influences SNs regarding compliance with work procedures.

H3c: Strengthening moral inhibition (education) influences perceived behavioural control over compliance with work procedures.

Shoham, Beck and Kett (2008, p. 352) state that for habitual law-abiding conduct to occur, strengthening of moral education becomes pivotal in this regard. Therefore, if an individual is taught morals that respond to what is stated in the law and to what degree compliance is rewarded and breaches punished, the individual is most likely to develop morality that leads to the birth of a culture of moral habits that promote law-abiding conduct.
In essence, an individual who has internalised and developed moral habits that promote law-abiding conduct will not see non-compliance as an alternative action and, therefore, will habitually behave in line with the law (Loughran, Piquero, Fagan, \& Mulvey, 2012). Such individuals have built a culture of morality and moral habits that support compliance. Hence, the fear of consequence for non-compliance will play a significant role in their choice of action. Therefore, this study hypothesised the following:

H4a: The stimulation of habitual law-abiding conduct (reinforcement) influences attitude towards compliance with work procedures.

H4b: The stimulation of habitual law-abiding conduct (reinforcement) influences SNs regarding compliance with work procedures.

H4c: The stimulation of habitual law-abiding conduct (reinforcement) influences PBC over compliance with procedures.

To this end, Figure 1 represents the developed hypothetical model.

\section{Method}

\section{Research design}

In this study, an exploratory cross-sectional survey research design was employed. According to Manerikar and Manerikar (2014, p. 95), 'exploratory research is the initial research conducted to clarify and define the nature of the problem'. The goal of exploratory research design is to formulate problems, clarify concepts and form hypotheses. Human behaviour in the development and design of work procedures in the field of local government has been barely researched (Nzewi, 2017). This study intended to clarify and define work procedures in local government as a tool to improve the level of compliance with legislation and regulation.

\section{Population and sampling}

The Buffalo City Metropolitan Municipality has 672 municipal officials (IDP, 2016/2021), and O.R Tambo District Municipality has 555 municipal officials (IDP Review, 2016). The target population of this study was derived from three departments, namely corporate services, infrastructure services, and budget and treasury. The total number of employees in the three departments was 220 for the Buffalo City Metropolitan Municipality and 195 for the O.R. Tambo District Municipality. All employees from senior managers to line officials were targeted in the study as work procedures need to be followed by everyone in an organisation.

This study sampled employees from the municipalities using non-probability sampling methods. According to Kumar (2014, p. 242), these are designs that are used when either the number of elements in a population is unknown or the elements cannot be individually identified. This research used snowball sampling technique. Two main issues informed this choice: the first is the nature of local government operations in the chosen municipalities, where there is a 


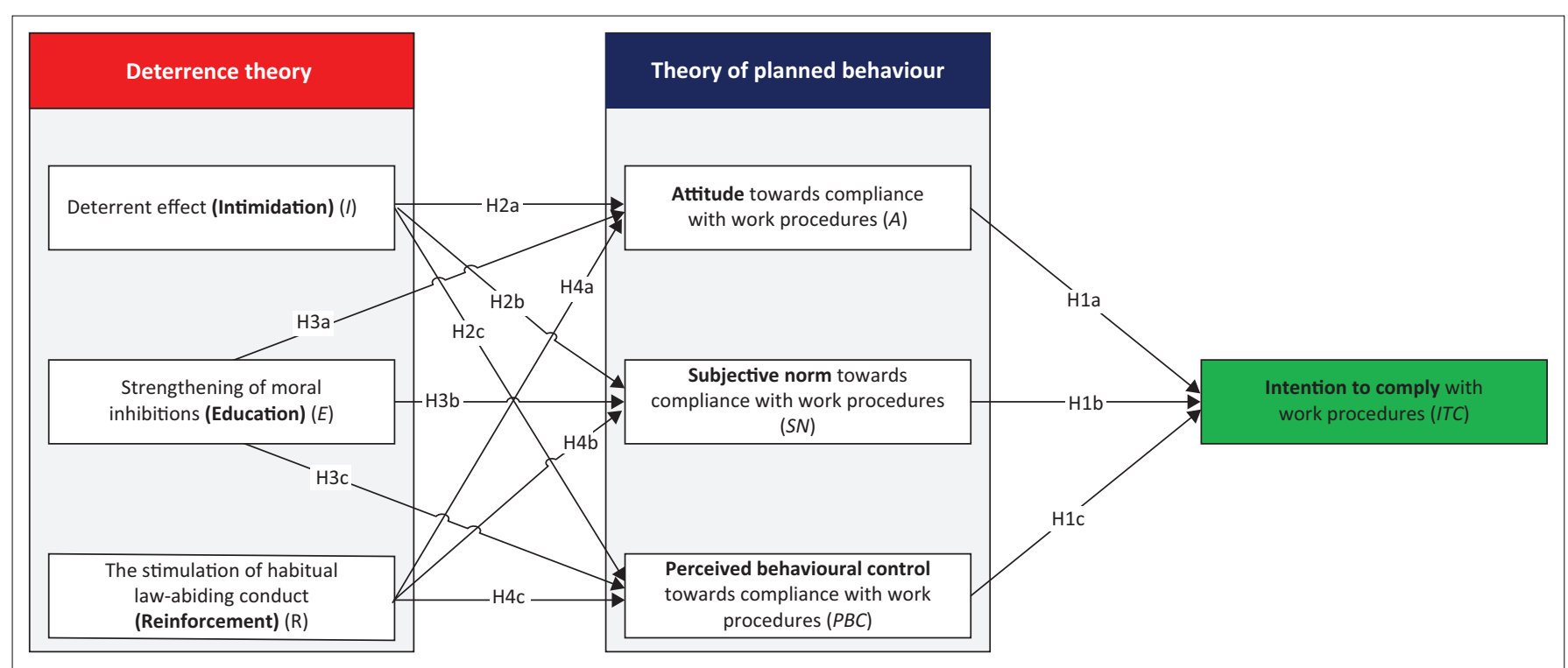

FIGURE 1: A proposed theory of planned behaviour and deterrence theory hypothetical model for managing workplace compliance.

marked difficulty in accessing respondents. The second is that snowball sampling augurs well for this research which is exploratory and where there is more focus on testing the relationship between variables than making generalisations. The directorates of the three departments identified for the study were required to provide information on suitable respondents for the study. In essence, they were asked to identify other people in their respective departments to become part of the sample. Then, the selected individuals of whom most were divisional and project heads were further asked to identify other suitable members within the departments. In turn, the identified individuals became the basis for further data collection.

\section{Sample size}

The Raosoft sample size calculator (2004) was used for the purposes of this study. The combined number of municipal officials of the two respective municipalities is 415 . The population targeted by the study were municipal workers of O.R Tambo District Municipality and Buffalo City Metropolitan Municipality. The response distribution was set at $50 \%$ for each question because the researchers did not know how the response rate would turn out. As the researchers had no way of knowing the skewness of either the population or sample prior, the $50 \%$ mark, which gives the largest sample size, was used. The margin of error was set at a minimum of $5 \%$ as any value lower than that would have required a significantly larger sample size. The confidence level was at a maximum of $95 \%$ because higher confidence levels would have required a larger sample size.

Furthermore, the sample size for this study was estimated based on the sample size required for factor analysis. Despite the seemingly known standards regarding reasonable absolute minimum sample size required for factor analysis, lack of consensus still persists in the literature. In some situations, practical conditions preclude a study from having sample size of up 100, 200, 500 and so on. Based on simulation models, it was found that some conditions are more critical in determining the right sample size. These conditions relate to a number of factors: factor loadings, number of variables and size of communalities. While Pearson and Mundform (2010) faulted the general rule of thumb regarding the reasonable absolute minimum sample size required to yield quality results, some scholars have argued that exploratory factor analysis (EFA) can produce results even from sample sizes below 50, provided that the factor loadings are high, the number of factors is low and the number of variables is high (De-Winter, Dodou, \& Wieringa, 2009). Therefore, the sample of 119 was considered adequate, given that the number of factors was low (seven factors); factor loadings were high, ranging from 0.62 to 0.99 ; and the number of variables involved were as high as 22 . The 119 questionnaires out of the 200 questionnaires administered represent a $60 \%$ response rate.

\section{Data analysis}

Data were entered and analysed in Statistical Package for Social Sciences (SPSS) version 25. The first step was to conduct data cleaning by screening cases and variables in the data set. This was performed to ensure that a clean data set for data analysis was generated. In the process of case screening, two participants were removed from the data set because they had over $13 \%$ missing values across the 22 indicators of latent variables. Other missing data less than $13 \%$ were replaced with near-point median values. Three missing values on the demographic variables were replaced with probable values deduced from contingency analyses performed. Thus, the sample size became 117. The possibility of participants ticking options at random leads to unengaged responses that could dilute the normality and validity of the data set. We therefore used standard deviation to check for this. Any standard deviation equals to 0 or close to 0.5 potentially shows that the participant probably had not fully engaged in the survey and was therefore removed. A total of 
11 cases whose standard deviations were less than 0.5 were thus removed. This further brought down the sample size to 106. A number of latent indicators violate the strict normality rule of \pm 1 in terms of kurtosis and skewness, although these values are within the more relaxed range recommended by Sposito, Hand and Skarpness (1983) who put the upper threshold at 3.3.

\section{Exploration}

Exploratory factor analysis was conducted to determine which of the 22 latent indicators adequately explained variation in the seven latent constructs involved in this study. Maximum likelihood method was used for the extraction of factors, while Promax rotation was used for the model optimisation with kappa set at 4 . Other criteria include eigenvalues $>1$, suppression of small coefficients set at $<0.3$ and loading factor $>0.6$. From the EFA results, the factor model obtained extracted factors with minimum eigenvalue of 1.052 which is greater than 1 . The extracted factors explain $63.607 \%$ of the total variance having only $9 \%$ non-redundant residuals with absolute values greater than 0.05 . The retained items were considered adequate based on the Kaiser-MeyerOlkin measure of sampling adequacy higher than $0.5(0.774)$ and a statistically significant Bartlett sphericity test $(<0.001)$.

\section{Validity and reliability}

Given that the questionnaire for this study was adopted from the study of Hadadgar et al. (2016), it became imperative to conduct confirmatory factor analysis (CFA). The aim of CFA was to ensure that the latent constructs, as measured by the questionnaire, satisfy construct, discriminant and convergent validity standards. IBM SPSS Amos version 25 was used to perform CFA and results are presented in the subsequent sections.

\section{Construct validity}

The CFA model fit indices show evidence of good construct validity (Hooper, Coughlan, \& Mullen, 2008). The CFA model has the following fit indices: relative chi-square $=1.245$, chisquare $=69.723, \mathrm{DF}=56, P=0.103$, comparative fit index $(\mathrm{CFI})=0.977$, incremental fit index $(\mathrm{IFI})=0.979$, TuckerLewis Index $(\mathrm{TLI})=0.963$, root mean square error of approximation $($ RMSEA $)=0.048, p$ of close fit $($ PCLOSE $)=$ 0.506 and standard root mean residual $(\mathrm{SRMR})=0.0503$.

\section{Discriminant validity}

To satisfy theory-testing criteria, discriminant validity was also tested. This idea is to ensure that a latent construct is not better explained by some other variables than by its own observed variables. Hair, Black, Babin and Anderson (2010) state that discriminant validity criterion must ensure that the maximum shared variance (MSV) for the latent constructs must be less than the corresponding average variance extracted (AVE) estimates. From the tables provided in Appendix 1, the criterion for discriminant validity was met for the six remaining constructs.

\section{Convergent validity}

Malhotra and Dash (2011) recommend that convergent validity be measured in a stricter way using AVE. They set the criterion that AVE should be greater than 0.5, implying that less than $50 \%$ of the variance should be because of error. Results showing that all AVE estimates are greater than 0.5 prove that our CFA models have good convergent validity.

\section{Reliability}

Composite reliability (CR) was estimated to ascertain the internal consistency for all the seven latent constructs. The criterion is that CR score above 0.7 is considered acceptable. From the results presented in Appendix 1, the CR scores range from 0.70 to 0.91 , thereby showing that items reliably measure the constructs involved in the study.

\section{Multivariate assumptions}

Multivariate assumptions were addressed by estimativng Cook's distance, tolerance values and variable inflation factor (VIF) using IBM SPSS version 25. We ran a Cook's distance analysis to determine if there were outliers and influential. Based on the threshold of Cook's distance $>1$, we observed that there were no influential observations as the highest Cook's distance is $<0.53$. As there was no persistently high Cook's distance in any case, no participant was removed. Tolerance and VIF were estimated to evaluate multicollinearity assumption. The least tolerance value obtained of 0.309 was greater than the required threshold of 0.1 , while most obtained VIF value hovered around 1.54. This value is less than the threshold of 3.00. These criteria being met indicate good multicollinearity.

\section{Structural equation model}

Having obtained good validity and reliability, a structural equation model (see Figure 3) was developed to include the latent constructs indicated in the theoretical framework (seeFigure 2). As a critical requirement, the structural model was tested for fitness with data set. As set by Hooper et al. (2008), the following indices show good fit: relative chi-square $\left(\chi^{2} / \mathrm{df}\right)=1.234, \mathrm{CFI}=0.976, \mathrm{TLI}=0.965, \mathrm{IFI}=0.977, \mathrm{RMSEA}=$ 0.047, PCLOSE $=0.529$ and SRMR $=0.0579$.

\section{Demographics and descriptive analysis}

Out of 106 participants, there were 42 male participants and 64 female participants representing approximately $40 \%$ and $60 \%$, respectively. A total of $58 \%$ of the respondents were supervisors, $16 \%$ were assistant managers and 10\% were managers, while $15 \%$ were senior managers. In terms of age, $43 \%$ of the respondents were below 25 years, while $35 \%$ were between ages 25 and 35 years. The remaining 22\% were between ages 36 and 45 years. About $54 \%$ had either a diploma or a bachelor's degree, while $23 \%$ had either honours or master's degree. Another 23\% had only matriculation (see Appendix 2 for details).

On a scale of 56, intimidation (I) has the lowest mean composite score at 2.40 (standard deviation $=1.11)$, while reinforcement 


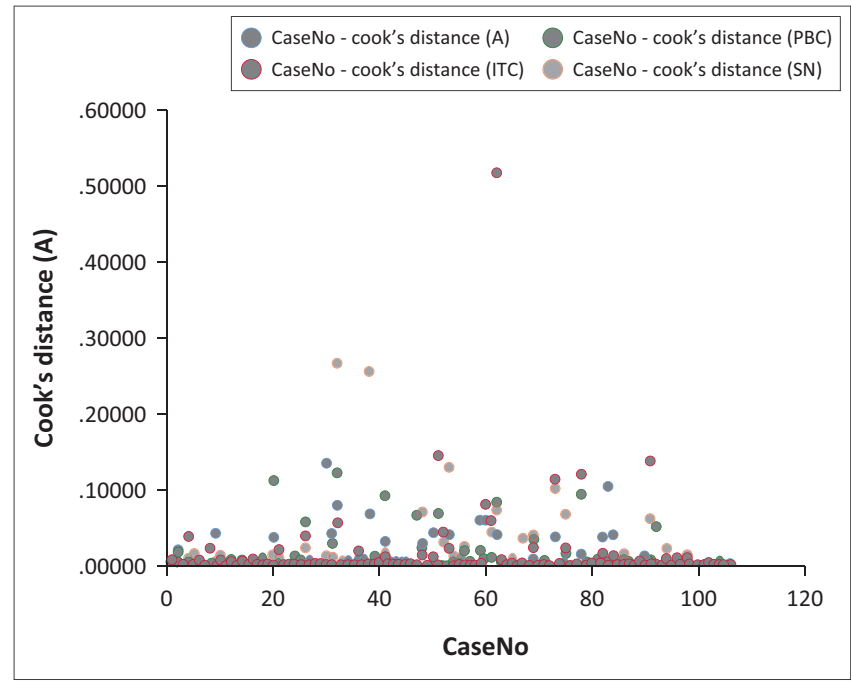

Note: Simple sca er of cook's distance (A), of cook's distance (SN), of cook's distance (PBC), of cook's distance (ITC) by caseNo.

FIGURE 2: Scatter graph showing non-significant outliers and influential.
(R) has the highest at 4.28 (standard deviation $=1.27$ ). Furthermore, all constructs were correlated to show their association sy performing a two-tailed bivariate correlation analysis. Results (see Table 1) show that all correlation coefficients were statistically significant at either $\alpha=0.05$ or $\alpha=0.01$.

\section{Hypotheses testing}

There were 12 sub-hypotheses involved in this explorative study. The structural equation model was used to estimate the regression weights of each path involved in the model and the $p$-value was computed (with $\alpha<0.05$ ) to determine the statistical significance of each regression weight. The results are presented in Table 2 .

The results presented in Table 2 show that only 6 out of 12 regression weights have statistical significance. From Table 2, the results indicate that intimidation (I) has a significantly negative influence on attitude (a component of TPB),

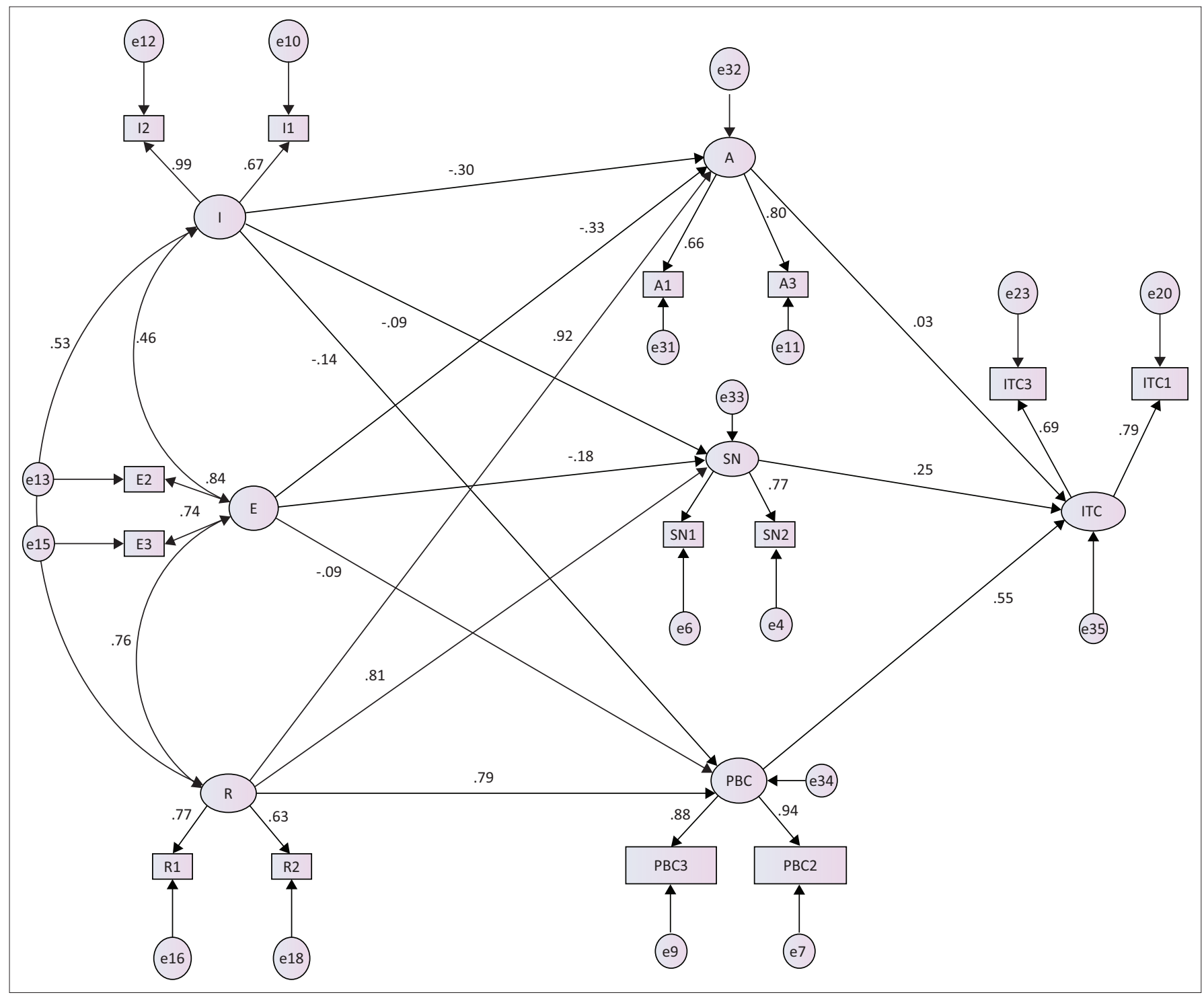

$\mathrm{SN}$, subjective norm; $\mathrm{PBC}$, perceived behavioural control.

FIGURE 3: Structural model of theory of planned behaviour and deterrence theory on managing work place compliance. 
TABLE 1: Matrix of correlation coefficients among study constructs.

\begin{tabular}{|c|c|c|c|c|c|c|c|}
\hline Variable & $I$ & $E$ & $\mathbf{R}$ & $A$ & SN & PBC & ITC \\
\hline 1 & 1 & & & & & & \\
\hline$E$ & $0.512 * *$ & 1 & & & & & \\
\hline R & $0.558^{* *}$ & $0.815^{* *}$ & 1 & & & & \\
\hline A & 0.039 & $0.307 * *$ & $0.512^{* *}$ & 1 & & & \\
\hline SN & $0.264 * *$ & $0.458 * *$ & $0.659 * *$ & $0.468 * *$ & 1 & & \\
\hline PBC & $0.226^{*}$ & $0.496 * *$ & $0.627 * *$ & $0.522 * *$ & $0.412 * *$ & 1 & \\
\hline ITC & $0.323^{* *}$ & $0.628 * *$ & $0.703^{* *} *$ & $0.468 * *$ & $0.544 * *$ & $0.746 * *$ & 1 \\
\hline
\end{tabular}

I, intimidation; E, estimate; R, reinforcement; $A$, attitude; SN, subjective norm; PBC, perceived behavioural control; ITC, intention to comply.

*, Correlation is significant at the 0.05 level (two-tailed).

**, Correlation is significant at the 0.01 level (two-tailed).

TABLE 2: Standardised regression weights.

\begin{tabular}{|c|c|c|c|c|}
\hline Regression paths & Estimate & Standard error & Critical ratio & $p$ \\
\hline$A<--1$ & -0.301 & 0.152 & -1.972 & 0.049 \\
\hline SN $<---1$ & -0.086 & 0.123 & -0.716 & 0.474 \\
\hline PBC $<---1$ & -0.144 & 0.136 & -1.19 & 0.234 \\
\hline$S N<---E$ & -0.179 & 0.197 & -0.845 & 0.398 \\
\hline$A<--E$ & -0.325 & 0.241 & -1.234 & 0.217 \\
\hline PBC $<---E$ & -0.092 & 0.213 & -0.448 & 0.654 \\
\hline$A<---R$ & 0.921 & 0.25 & 3.168 & 0.002 \\
\hline$S N<---$ R & 0.807 & 0.224 & 3.159 & 0.002 \\
\hline$P B C<---R$ & 0.792 & 0.223 & 3.464 & $* * *$ \\
\hline ITC $<---A$ & 0.027 & 0.127 & 0.214 & 0.831 \\
\hline ITC $<---S N$ & 0.246 & 0.112 & 2.132 & 0.033 \\
\hline$I T C<---P B C$ & 0.548 & 0.11 & 4.351 & $* * *$ \\
\hline
\end{tabular}

I, intimidation; $E$, estimate; $R$, reinforcement; $A$, attitude; $S N$, subjective norm; $P B C$, perceived behavioural control; ITC, intention to comply.

$* * *, p<0.001$ in amos.

A $(r=-0.301, p=0.049)$. The implication is that attitude towards compliance with work procedure will decrease by an estimated $30 \%$ because of a proportionate increase in the use of intimidation. Intimidation therefore is not a good tool for fostering the right and ethical attitude towards workplace procedures compliance.

Results also show that reinforcement, $\mathrm{R}$, has significantly positive impact on attitude, $A(r=0.921, p=0.002)$, $S N$ $(r=0.807, p=0.002)$ and PBC $(r=0.792, p<0.001)$. These imply that attitude will increase by $92 \%$, SN by $81 \%$ and PBC by $80 \%$ as reinforcement increases by $100 \%$. Reinforcement therefore is a very significant deterrence factor having high impact on TPB.

Similarly, SN $(r=0.246, p=0.033)$ and PBC $(r=0.548$, $p<0.001)$ have a significantly positive impact on ITC with work procedures. This implies that as SN increases by $100 \%$, there will be a corresponding increase in ITC with work procedures by $25 \%$; while $100 \%$ increase in PBC will result in a corresponding $55 \%$ increase in ITC with work procedures.

From the structural model, nine mediated paths were tested and the results are presented in Table 3. The results show that only two mediated paths are statistically significant at $p<0.05$. In other words, $\mathrm{SN}$ significantly mediates between reinforcement and ITC with work procedures at $r=0.170$ and $p=0.045$. Thus, $\mathrm{SN}$ has a $17 \%$ mediating effect between reinforcement and ITC. Similarly, PBC has a 37\% mediating
TABLE 3: Standardised regression weights.

\begin{tabular}{|c|c|c|c|c|}
\hline Mediated paths & Estimate & Lower & Upper & $p$ \\
\hline ITC $<---A<---\mid$ & -0.008 & $\ldots$ & 0.801 & 0.653 \\
\hline$I T C<---A<---E$ & -0.008 & $\ldots$ & 0.172 & 0.396 \\
\hline ITC $<---A<---~ R$ & 0.022 & -2.515 & $\ldots$ & 0.702 \\
\hline ITC $<---$ SN $<---I$ & -0.021 & $\ldots$ & 0.048 & 0.204 \\
\hline ITC $<---\mathrm{SN}<---\mathrm{E}$ & -0.040 & $\ldots$ & 0.089 & 0.172 \\
\hline ITC $<---$ SN $<---~ R$ & 0.170 & -0.056 & $\ldots$ & 0.045 \\
\hline ITC $<---P B C<---1$ & -0.078 & $\ldots$ & 0.634 & 0.285 \\
\hline ITC $<---P B C<---E$ & -0.046 & $\ldots$ & 0.432 & 0.531 \\
\hline ITC $<---P B C<---R$ & 0.370 & -2.938 & $\ldots$ & 0.035 \\
\hline
\end{tabular}

I, intimidation; $E$, estimate; $R$, reinforcement; A, attitude; $S N$, subjective norms; $P B C$, perceived behavioural control; ITC, intention to comply.

effect between ITC with work procedures significantly at $p=0.035$.

\section{Ethical consideration}

This article followed all ethical standards for a research without direct contact with human or animal subjects.

\section{Findings and discussion}

The findings of the study reveal that a positive attitude towards compliance to work procedures cannot be achieved through intimidation. In contrast to the deterrent effect (intimidation) that is largely regarded as an essential tenet of the DT that can be adopted to foster compliance to work procedures, the results of this study show that intimidation cannot always bear positive results on employee attitude. The study by Bates, Darvel and Watson (2017) on the use of deterrence to explain provisional drivers' non-compliance found that drivers exposed to higher levels of enforcement for traffic and speeding offences were less compliant. This is in a similar vein to Havov and Putri's (2016) assertion that employees' compliance with ethical conduct is to a greater extent influenced by the employees' personal norms and moral standards rather than intimidation. This finding is in contrast with the doctrine of DT which states that punishing an individual for a crime should discourage them from committing it again. The insinuation presented here is that the use or the threat of punishment or sanctions with the intention to avoid employees breaking the law at workplace has a negative bearing on employee attitude; hence, it cannot be considered a good practice in establishing an organisational culture of compliance to work procedures. The implication for municipal practice is that enforcing employee ethical codes of conduct through intimidation as a means to deterrence can result in employees having a negative attitude towards work procedures and hence non-compliance. This can result in negative consequences on the general performance of municipalities. This is further elucidated by Bireswari (2013) who asserts that negative employee attitude is a contributing variable to poor organisational performance. In this regard, the study suggests that the application of intimidation at managerial levels may stifle efforts towards the establishment of a positive attitude on compliance to work procedures. 
Reinforcement has a positive effect on attitude, SN and PBC. This supports the notion that the stimulation of a habitual law-abiding conduct (reinforcement) in organisations can be adopted and used as a condition sine-qua-non for the establishment of positive compliant behaviour and control. In other terms, the absence of reinforcement may dwarf an organisation's efforts that are geared towards the establishment of these dependent variables. To obtain desirable results for organisations (municipalities in this study context), managers need to increase reinforcement through monitoring compliance with work procedures, communication of work procedures and review of work procedures after a reasonable period. Other studies (Maritim, 2016; Wei \& Yazdanifard, 2014) also reflect a significant contribution of positive reinforcement in changing attitude, SNs and PBC at the workplace. The implication for municipal managerial practice is that workplace motivation, attitude and SNs can be subdued if positive reinforcement is not taken into consideration.

This study also finds that PBC is the only aspect of TPB that significantly affects ITC with work procedures. The study by Herath and Rao (2009) on information systems security compliance revealed that evidence from many contexts shows greater PBC influence on behaviour than measures of attitude and SN. This is in line with the research that found that intent to comply could be limited by factors beyond the individuals' control, such as time, cost, resistance from others (interference) and skill to perform such task. For instance, Dzansi, Chipunza and Monnapula-Mapesela (2016) found a positive relationship between political interference and how employees perceive fairness in HRM practices. According to Nzewi (2017), within the context of local government in South Africa, intentions or motivations to behave cannot be sufficient. This is because municipalities in South Africa have become the locus of capacity and skills dearth and political tensions. These are conditions that limit the ability and capability to behave in terms of volitional control. From this perspective, $\mathrm{PBC}$ can be useful in predicting compliance behaviour. Therefore, this implies that municipalities must give consideration to the perceived difficulties or barriers directly limiting one from carrying out a behavioural intent and the confidence one has regardless of internal or external environment.

The above implies that there is only a partial mediation between DT and ITC involving SN, PBC and reinforcement. The principal variable that will most likely result in the ITC therefore is the interaction between reinforcement and PBC. This suggests that reinforcement from managers is boosted by employees' positive perceptions of their ability and capability to carry out the particular compliance task.

\section{Conclusion}

This study used empirically based literature on the TPB and DT to develop a hypothetical model for local government compliance. The model was tested to find the mediating role of planned behaviour on deterrence initiatives aimed at compliance behaviour. In answering the two research questions, the results show that a positive attitude towards compliance to work procedures cannot be achieved through intimidation mechanisms of sanctions and punishment of municipal employees. This result is in contrast to the deterrent effect that is generally regarded as essential to foster in compliance. Indeed, the results reveal that reinforcement has a positive effect on attitude, SN and PBC. This makes reinforcement a pivotal and important instrument that municipalities and similar organisations can adopt and use to establish a culture of compliance with work procedures. Furthermore, the results reveal PBC to be the only antecedent of TPB to significantly affect the ITC with work procedures. What this says in terms of the mediating role of planned behaviour on ITC is that where there is reinforcement or habitual stimulation of law-abiding conduct, the negative impact of employees' perceptions of conditions which limit their ability and capability to behave (PBC) is curtailed. This improves employees' likelihood to comply. The importance of these findings is that they inform municipalities to consider reinforcement measures that grow compliance behaviour and measures to increase employees' perceived lack of ability or capability to perform a task (e.g. training). These measures will limit the perceived difficulties or barriers that directly limit employees from carrying out tasks and duties related to compliance.

\section{Acknowledgements}

The Department of Public Administration, University of Fort Hare.

\section{Competing interests}

The author(s) declare that they have no financial or personal relationship(s) that may have inappropriately influenced them in writing this article.

\section{Authors' contributions}

Mr S. Lungisa is the main author of this article as it is derived from his master's research submitted to the University of Fort Hare. He was responsible for data collection, interpretation of results and writing a substantial part of the manuscript. Prof. O. Nzewi is the appointed supervisor of $\mathrm{Mr}$ S. Lungisa by the University of Fort Hare. She was responsible for guiding Mr S. Lungisa throughout the master's degree and other requirements as mandated by the university. Dr S.O. Olutuase contributed to the methods, data analysis and part of findings sections of this article. He also helped in designing the theoretical framework as well as structuring the hypotheses.

\section{Funding information}

This work is based on the research supported wholly or in part by the National Research Foundation of South Africa (Grant Number 98866). 


\section{Data availability statement}

Data sharing is not applicable to this article as no new data were created or analysed in this study.

\section{Disclaimer}

We declare that this research article hereby submitted to the South African Journal of Human Resources Management (SAJHRM) for publication has not previously been submitted by us for publication in any other journal besides SAJHRM, that it is our work in design and execution and that all material contained herein has been duly acknowledged.

\section{References}

Auditor General of South Africa (AGSA). (2016). Consolidated general report of the audit outcomes of local government [online]. Retrieved from www.agsa.co.za

Ajzen, I., \& Fishbein, M. (1973). Attitudinal and normative variables as predictors of specific behavior. Journal of Personality and Social Psychology, 27(1), 41-57. https://doi.org/10.1037/h0034440

Ajzen, I. (1991). The theory of planned behaviour. Organizational behaviour and human decision processes. Journal of Applied Social Psychology, 50(2), 179-211. https://doi.org/10.1016/0749-5978(91)90020-T

Ajzen, I. (2005). Attitudes, personality and behavior. Maidenhead: Open University Press.

Ajzen, I. (2006). Constructing a theory of planned behaviour questionnaire: Conceptual and methodological considerations. Retrieved from https://www.people.umass. edu/aizen/pdf/tpb.measurement.pd

Bates, L., Darvell, M. J., \& Watson, B. (2017). Young and unaffected by road policing strategies: Using deterrence theory to explain provisional drivers' (non) compliance. Australian and New Zealand Journal of Criminology, 50(1), 23-38. https://doi.org/10.1177/0004865815589824

Beyleveld, D. (1979). Deterrence research as a basis for deterrence policies. The Howard Journal of Crime and Justice, 18(3), 135-149. https://doi.org/10.1111/ j.1468-2311.1979.tb00388.x

Bireswari, V. R. (2013). Organizational performance with employee attitude and behavior respect to IT industry, Bangalore: An empirical study. Retrieved from https://ssrn.com/abstract=2210737

Conner, M., Norman, P., \& Bell, R. (2002). The theory of planned behaviour and healthy eating. Health Psychology, 21(2), 194-201. https://doi.org/10.1037/02786133.21.2.194

De-Winter, J.C.F., Dodou, D., \& Wieringa, P.A. (2009). Exploratory factor analysis with small sample sizes. Multivariate Behavioral Research, 44(2), 147-181. https://doi. org/10.1080/00273170902794206

Dzansi, L.W., Chipunza, C., \& Monnapula-Mapesela, M. (2016). Municipal employees' perceptions of political interference in human resource management practices: Evidence from the Free State Province in South Africa. International Business \&amp; Economics Research Journal (IBER), 15(1), 15-26. https://doi. \&amp; Economics Research
org/10.19030/iber.v15i1.9572

Elliott, B. (2003). Deterrence theory revisited. Paper presented at the road safety research, policing and education conference, 24-26 September 2003. Sydney, NSW: Roads and Traffic Authority (RTA)

Fishbein, M., \& Ajzen, I. (2010). Predicting and changing behaviour: The reasoned action approach. New York: Psychology Press.

Hadadgar, A., Changiz, T., Masiello, I., Dehghani, Z., Mirshahzadeh, N., \& Zary, N. (2016). Applicability of the theory of planned behaviour in explaining the general practitioners elearning use in continuing medical education. BMC Medical Education Journal, 16(1), 1-8.

Hair, J., Black, W., Babin, B., \& Anderson, R. (2010). Multivariate data analysis (7th ed.). Upper Saddle River, NJ: Prentice-Hall, Inc.

Havov, A., \& Putri, F.F. (2016). This is my device! Why should I follow your rules? Employees' compliance BYOD security policy. Pervasive and Mobile Computing, 32 (2016), 35-49.
Hawkins, G. (1969). Punishment and deterrence: The educative, moralizing, and habituative effects. UW-Madison: Wisconsin Law Review.

Herath, J., \& Rao, H. (2009). Protection motivation and deterrence: A framework for security policy compliance in organisations. European Journal of Information Systems, 18(2), 106-125. https://doi.org/10.1057/ejis.2009.6

Hooper, D., Coughlan, J., \& Mullen, M. (2008). Structural equation modelling: Guidelines for determining model fit. The Electronic Journal of Business Research Methods, 6(1), 53-60. Retrieved from www.ejbrm.com

Ijeoma, E., \& Nzewi, O.I. (2016). Work procedures application in municipal government: Perspective from local government employees in South Africa. Journal of Public Administration, 51(1), 58-72.

Johnson, B. (2019). Do criminal laws deter crime? Deterrence theory in criminal justice policy: A primer, Minnesota House Research Department. Retrieved from https://www.house.leg.state.mn.us/hrd/pubs/deterrence.pdf

Kumar, R. (2014). Research methodology a step-by-step guide for beginners (4th ed.) Los Angeles, CA: Sage.

Loughran, T., Piquero, A.R., Fagan, J., \& Mulvey, E.P. (2012). Differential deterrence: Studying heterogeneity and changes in perceptual deterrence among serious adolescent offenders. Crime \& Delinquency, 58(1), 3-27. https://doi.org/ $10.1177 / 0011128709345971$

Malhotra, N.K., \& Dash, S. (2011). Marketing research an applied orientation. London: Pearson Publishing.

Manerikar, V., \& Manerikar, S. (2014). A note on exploratory research. A Peer Reviewed Research Journal, 17(1), 95-96.

Maritim, D.K. (2016). The influence of positive reinforcement on employee motivation at the Nakuru country government. IOSR Journal of Business Management, 18(9), 16-19. https://doi.org/10.9790/487X-1809021619

Nzewi, O.I. (2017). Managing municipal audit compliance through work procedures: A theory of planned behaviour approach. Southern African Journal of Accountability and Auditing, 19(1), 1-14.

Peace, A.G., Galletta, D., \& Thong, J. (2003). Software piracy in the workplace: A model and empirical test. Journal of Management Information Systems, 20(1), 153-177. https://doi.org/10.1080/07421222.2003.11045759

Pearson, R.H., \& Mundform, D.J. (2010). Recommended sample size for conducting exploratory factor analysis on dichotomous data. Journal of Modern Applied Statistical Methods, 9(2), 359-368. https://doi.org/10.22237/jmasm/1288584240

Republic of South Africa. (2009). Local government turnaround strategy. Pretoria: Government Printers.

Republic of South Africa. (2014). Back to basic approach. Pretoria: Government Printers.

Republic of South Africa. (2016a). Buffalo City Metropolitan Municipality Integrated Development Plan 2016-2021. East London: Government Printers.

Republic of South Africa. (2016b). O.R Tambo district municipality integrated development plan review 2016/2017. Umtata: Government Printers Works.

Schneider, A., (2019). Deterrence theory in Paraguay: Exploring fraud and violation of trust cases. Social Sciences, 8(23), 1-17. https://doi.org/10.3390/socsci8010023

Shoham, S.G., Beck, O., \& Kett, M. (2008). International handbook of penology and criminal justice. Raton, NM: CRC Press.

Sposito, V.A., Hand, M.L., \& Skarpness, B. (1983). On the efficiency of using the sample kurtosis in selecting optimal $I_{\text {p }}$ estimators. Communications in Statistics-Simulation and Computation, 12(3), 265-272. https://doi.org/ 10.1080/03610918308812318

Wei, L.T., \& Yazdanifard, R. (2014). The impact of positive reinforcement on employees' performance in organisations. American Journal of Industrial and Business Management, 2014 (4), 9-12. https://doi.org/10.4236/ajibm.2014.41002

Wikström, P.O.H., \& Treiber, K. (2007). The role of self-control in crime causation European Journal of Criminology, 4(2), 237-264. https://doi.org/10.1177/ 1477370807074858

Wikström, P.O.H. (2010). Situational action theory. In F. T. Cullen \& P. Wilcox (Eds.) Encyclopedia of criminological theory, (pp. 3-43). London, England: Sage.

Williams, K., \& Hawkins, R. (1986). Perceptual research on general deterrence: A critical overview. Law and Society Review, 20(4), 545-572. https://doi.org/10. 2307/3053466

Zhang, K. (2018). Theory of planned behavior: Origins, development and future direction. International Journal of Humanities and Social Science Invention, 7(5), 76-83. 


\section{Appendix 1}

TABLE 1-A1: Validity and reliability measures.

\begin{tabular}{|c|c|c|c|c|c|c|c|c|c|c|c|}
\hline & CR & AVE & MSV & $\operatorname{MaxR}(\mathrm{H})$ & A & SN & PBC & 1 & E & $\mathbf{R}$ & ITC \\
\hline A & 0.7 & 0.54 & 0.2 & 0.735 & 0.737 & - & - & - & - & - & - \\
\hline SN & 0.87 & 0.78 & 0.353 & 0.969 & $0.404 * *$ & 0.880 & - & - & - & - & - \\
\hline PBC & 0.91 & 0.84 & 0.424 & 0.938 & $0.448 * * *$ & $0.394 * *$ & 0.915 & - & - & - & - \\
\hline I & 0.83 & 0.72 & 0.257 & 0.989 & 0.033 & $0.258^{*}$ & $0.218 \dagger$ & 0.849 & - & - & - \\
\hline E & 0.77 & 0.62 & 0.499 & 0.769 & $0.239 \dagger$ & $0.406 * *$ & $0.435 * * *$ & $0.459 * *$ & 0.788 & - & - \\
\hline $\mathbf{R}$ & 0.71 & 0.55 & 0.499 & 0.744 & $0.424 * *$ & $0.594 * * *$ & $0.560 * * *$ & $0.507 * *$ & $0.706 * * *$ & 0.742 & - \\
\hline ITC & 0.71 & 0.55 & 0.424 & 0.719 & $0.364 *$ & $0.475 * *$ & $0.651 * * *$ & $0.284 *$ & $0.517 * * *$ & $0.576 * * *$ & 0.740 \\
\hline
\end{tabular}

AVE, average variance extracted; MSV, maximum shared variance; A, attitude; ITC, intention to comply; I, intimidation; E, estimate; $R$, reinforcement; SN, subjective norm; PBC, perceived behavioural control.

Significance of correlations: $\dagger p<0.100,{ }^{*} p<0.050,{ }^{* *} p<0.010, * * * p<0.001$.

\section{Appendix 2}

TABLE 1-A2: Demographic details.

\begin{tabular}{lll}
\hline Variable & $N$ & $\%$ \\
\hline Gender & 42 & 40 \\
Male & 64 & 60 \\
Female & & \\
Job position & 16 & 15 \\
Senior manager (sec 53 and 56) & 11 & 10 \\
Manager & 17 & 16 \\
Assistant manager & 62 & 58 \\
Supervisor & & \\
Department & 40 & 38 \\
Finance & 31 & 29 \\
Human resources & 26 & 25 \\
Infrastructure & 9 & 8 \\
Others & & \\
Municipality & 65 & 61 \\
O.R Tambo District Municipality & 41 & 39 \\
Buffalo City Metropolitan Municipality & & \\
Age bracket & 46 & 43 \\
$<25$ years old & 37 & 35 \\
25-35 years old & 23 & 22 \\
$36-45$ years old & & \\
Educational level & 24 & 23 \\
Matric certificate & 57 & 54 \\
Diploma-bachelor's degree & 23 \\
Honours-master's degree & & \\
\hline & & \\
\hline
\end{tabular}

